\title{
A TEMPESTADE GLOBAL DA LEI E ORDEM: SOBRE PUNIÇÃO E NEOLIBERALISMO ${ }^{1}$
}

\author{
Loïc Wacquant
}

\begin{abstract}
RESUMO
Este artigo reflete sobre a recepção internacional ao livro Prisões da miséria como reveladora da expansão penal nas sociedades avançadas na década de 2000. Ele revela que a tempestade global da "lei e ordem" inspirada pelos Estados Unidos, que o livro detectou em 1999, continuou a espalhar-se por toda a parte. Na verdade, ela estendeu-se dos países do Primeiro Mundo para os do Segundo Mundo e alterou a política e as práticas de punição em todo o globo de uma forma que ninguém previa e que ninguém teria pensado como possivel há cerca de 15 anos. $O$ artigo estende a análise para o papel dos institutos de consultoria (em especial o Manhattan Institute) na difusão das noções de combate ao crime e das panacéias no estilo estadunidense na América Latina como um elemento da circulação internacional dos pacotes de política pró-mercado que alimentam a gerência punitiva da pobreza. O artigo elabora e revê o modelo original do nexo entre neoliberalismo e penalidade punitiva, levando a análise da montagem do Estado na era da insegurança social, desenvolvida no livro Punindo os pobres.
\end{abstract}

PALAVRAS-CHAVE: Justiça Criminal; tolerância zero; institutos de consultoria; Estado Penal; transferência de políticas; neoliberalismo; globalização.

\section{INTRODUÇÃO}

No início da década de 1990, o novo Prefeito republicano da cidade de Nova York, Rudolph Giuliani, lançou a campanha de policiamento conhecida por "Tolerância Zero", voltada para o combate das desordens de rua e dos pequenos infratores, encarnada pelo notório "lavador de carro". Nova York logo se tornou uma vitrine para uma agressiva abordagem da aplicação da lei que, a despeito de seus custos extravagantes e da ausência da conexão com a queda da criminalidade, passou a ser admirada e imitada

\footnotetext{
1 A ser publicado em Thesis Eleven (versão de 27 de fevereiro de 2011); agradecemos ao autor a gentileza de autorizar a tradução para o português do artigo. Este texto baseia-se no posfácio de Prisons of Poverty (WACQUANT, 2009a), a edição revista e ampliada em língua inglesa do livro em francês Les Prisons de la misère (1999). O trabalho original beneficiou-se do apoio de uma bolsa da MacArthur Foundation, do inigualável estímulo intelectual de Pierre Bourdieu e da generosidade profissional de colegas em Criminologia e Penologia de instituições de pesquisa em três continentes. Uma bolsa da Alfonse Fletcher facilitou as revisões do livro, bem como a preparação deste artigo. Tradução de Sérgio Lamarão e revisão da tradução de Gustavo Biscaia de Lacerda.
}

por outras cidades nos Estados Unidos e na Europa Ocidental. Em meu livro Prisões da miséria, publicado pela primeira vez em 1999, traço a incubação e a internacionalização de motes ("a prisão funciona"), teorias ("vidraças quebradas") e iniciativas (tais como a ampliação do encarceramento, sentenças mínimas obrigatórias, campos de treinamento correcionais e a adoção do toque de recolher para jovens), compondo esse novo "senso comum" punitivo, moldado para controlar as crescentes desigualdade e marginalidade urbanas nas metrópoles (WACQUANT, 2009a). Verifico que uma rede de institutos de consultoria conservadores da era Reagan, liderados pelo Manhattan Institute, forjou-as como arma em sua cruzada para desmantelar o Estado do Bem-estar e, para todos os efeitos, criminalizar a pobreza, tendo como pano de fundo a ampliação da desigualdade econômica e da difusão da insegurança social. Traço sua importação-exportação por meio da ação de políticos obcecados com a visão neoliberal, dos grandes meios de comunicação e dos institutos de opinião pró-mercado que se multiplicaram pela União Europeia, particularmente na Grã-Bretanha de Tony Blair. Por fim, mostro como os intelectuais locais ajudaram a 
contrabandear técnicas de penalização estadunidenses para seus países, vestindo-as com roupagens acadêmicas. Meu argumento central estabelece um elo entre a reestruturação neoliberal e a punição: o "Consenso de Washington" sobre a desregulamentação econômica e a retração do Estado do Bem-estar foi ampliado para abranger o controle do crime punitivo porque a "mão invisível" do mercado necessita do "punho de ferro" do Estado penal e convoca-o.

Reflito, neste artigo, sobre a recepção internacional de Prisões da miséria (idem) - que em pouco tempo foi traduzido para 20 línguas como reveladora da expansão penal em sociedades avançadas ao longo da década de 2000. Mostro que a tempestade global da "lei e ordem", inspirada pelos Estados Unidos que o livro detectou em 1999, continuou a espalhar-se por toda a parte. Em termos concretos, estendeu-se dos países do Primeiro Mundo para os do Segundo Mundo e alterou a grande política e as políticas específicas de punição em todo o planeta de uma forma que ninguém previu e ninguém pensaria ser possível há cerca de 15 anos. Estendo a análise do papel dos institutos de consultoria na difusão do estilo americano de penalidade na América Latina (o que foi chamado de "fator Giuliani"). Finalmente, elaboro e revejo o modelo original do nexo entre neoliberalismo e penalidade punitiva, fundamental para a análise da modelagem do Estado na era da insegurança social desenvolvida em meu livro Punindo os pobres (WACQUANT, 2009b).

II. RASTREANDO A TEMPESTADE GLOBAL DA “LEI E ORDEM" AO REDOR DO MUNDO

Prisões da miséria utiliza as ferramentas das Ciências Sociais para lançar, e sustentar, um debate público que é de extrema significação social em países ocidentais. O eixo do debate é o papel cada vez mais crucial da prisão e da virada punitiva na política penal, discernível nas sociedades mais avançadas a partir das duas últimas décadas do século XX. O alvo inicial foi a França e seus vizinhos, na condição de ávidos importadores de categorias, motes e medidas de controle da criminalidade, elaborados durante a década de 1990 nos Estados Unidos como veículos para a substituição histórica do bem-estar social pela gestão penal da marginalidade urbana, feita por esse país. O objetivo do livro foi escapar da política e do discurso dos meios de comunicação dominantes que promovem a difusão dessa nova doxa punitiva e alertar os acadêmicos, líderes civis e cidadãos interessados da Europa para as origens duvidosas dessa difusão, bem como para as terríveis consequências sociais e os perigos políticos do crescimento e da glorificação do braço penal do Estado.

No momento em que o escrevi não esperava aventurar-me mais profundamente no que era então para mim um campo de investigação novo e estranho. Eu havia trazido o aparato da Justiça Criminal para meu âmbito analítico em razão de seu estupendo crescimento no gueto negro em implosão nos Estados Unidos e de sua utilização agressiva em torno dele, após o declínio do movimento pelos direitos civis, e estava firmemente decidido a retomar as questões da desigualdade urbana e da dominação etno-racial ${ }^{2}$. Ao longo do caminho, porém, dois acontecimentos inesperados estimularam-me a continuar nessa linha de pesquisa e de ativismo intelectual.

O primeiro foi a acolhida incomum que o livro teve na França e depois nos países que se apressaram a traduzi-lo, cruzando as fronteiras que separam o conhecimento científico, a militância cidadã e a formulação de políticas. O segundo foi o fato de que a dupla tese que ele propõe - que um novo "bom senso punitivo", forjado nos Estados Unidos como parte do ataque ao Estado de Bem-estar, está atravessando rapidamente o Atlântico para ramificar-se pela Europa Ocidental, e que essa disseminação não é uma resposta interna a mudanças na incidência e no perfil da criminalidade, mas antes um fruto da difusão externa do projeto neoliberal - recebeu uma espetacular e evidente validação quando Les Prisons de la misère foi publicado em uma dúzia de línguas no espaço de poucos anos após seu lançamento.

Essa reação estrangeira apaixonada proporcionou-me a oportunidade de viajar por três continentes para pôr à prova a viabilidade e a

2 Começando pela lógica da polarização urbana a partir de baixo nos Estados Unidos e na Europa, investigada em Urban Outcasts: A Comparative Sociology of Urban Marginality (WACQUANT, 2008a), estabeleço as conexões analíticas entre minhas investidas na desigualdade urbana e na punição em The Body, the Ghetto and the Penal State (WACQUANT, 2009c). 
pertinência de seus argumentos. Permitiu-me verificar que a popularidade global do "modelo nova-iorquino" de policiamento, encarnado pelo ex-Chefe de Polícia de Nova York William Bratton e pelo Prefeito que o contratara (e que o demitiu), Rudolph Giuliani, é de fato a ponta do iceberg de uma reforma maior da autoridade pública, um elemento em uma cadeia mais ampla de transferência transnacional de políticas que abarca a reorganização flexível do mercado de trabalho desqualificado e a transformação restritiva do welfare no workfare $^{3}$, segundo o modelo fornecido pelos Estados Unidos pós-fordistas e pós-keynesianos ${ }^{4}$. Um relato seletivo da trajetória meteórica da edição original de As prisões da miséria por meio de esferas de debate e fronteiras nacionais pode ajudar-nos a discernir melhor o que está em jogo na discussão intelectual e nas lutas políticas a que ele alia-se, as quais dizem respeito menos ao crime e à punição e mais à reengenharia do Estado para promover as condições econômicas e sociomorais que se aglutinam sob o neoliberalismo hegemônico e que buscam responder a elas.

Desde o princípio, o livro transpôs as fronteiras entre as esferas acadêmica, jornalística e civil. Na França, Les Prisons de la misère foi literalmente lançado a partir do coração da instituição carcerária: em uma tarde cinzenta e fria de novembro de 1999, apresentei, ao vivo, os frutos das minhas investigações no Canalweb e na Télé la Santé, uma estação de televisão interna, dirigida pelos detentos na prisão de La Santé, no centro de Paris. Mais tarde voltei a debatê-los, noite adentro, com todo o staff e recrutas da Escola Nacional de Treinamento para Pessoal Correcional

\footnotetext{
3 Workfare designa, segundo o próprio autor, programas de assistência pública destinados aos pobres, que fazem do recebimento do auxílio um benefício pessoal condicional, quando os beneficiários aceitam trabalho mal remunerado ou submetem-se a estratégias orientadas para o emprego, tais como o treinamento no local do trabalho ou jobsearching; o workfare opõe-se ao welfare, enquanto um direito inquestionável à assistência (nota do tradutor).

4 O impulso diferencial para a desregulação do mercado de trabalho nas nações pós-industrializadas é analisado por Boje (1993), Esping-Andersen e Regini (2004) e Koch (2006). A difusão e a adaptação do workfare de inspiração estadunidense para outras sociedades avançadas são acompanhadas por Trickey e Loedemel (2001), Peck (2001) e Handler (2004)
}

em sua cantina lotada, bem perto da cidade. Em poucas semanas, a discussão estendeu-se aos principais órgãos de imprensa e a uma gama variada de foros acadêmicos e de ativistas, que incluía desde a École Normale Supérieure, em Paris, até a feira anual do partido trotskista Lutte Ouvrière, passando pela Maison des Sciences de l'Homme, em Nantes, por um "debate de bar" promovido pelo Partido Verde em Lyon, pelo Centro Nacional de Pesquisa Científica e pela École de la Magistrature (a academia francesa para os juízes). Participei igualmente de encontros públicos por todo o país, patrocinados por entidades tão variadas quanto Les Amis du Monde Diplomatique, a Anistia Internacional, Association pour la Taxation des Transactions pour l'Aide aux Citoyens (Associação pela Tributação das Transações Financeiras para Ajuda aos Cidadãos - Attac), a Liga dos Direitos do Homem, Raisons d'Agir, o Genepi (uma associação nacional de estudantes que desenvolve programas educacionais para presidiários), universidades locais e associações de bairro, vários partidos políticos e uma das maiores lojas maçônicas do país. Um encontro público sobre "A punição da pobreza" que durou o dia todo, organizado em maio de 2000 na Maison des Syndicats em Montpellier, minha cidade natal, exemplificou esse espírito de discussão aberta e vigorosa, reunindo cientistas sociais, advogados e magistrados, além de ativistas e representantes dos sindicatos, abarcando os mais diversos braços do Estado: educacional, da saúde, previdenciário, da Justiça para a juventude e correcional ${ }^{5}$.

Logo Les Prisons de la misère foi adaptado para o teatro (e encenado nos Rencontres de la Cartoucherie, em junho de 2000); seus argumentos inseridos em filmes publicitários; trechos seus reproduzidos em antologias acadêmicas, fanzines libertários e publicações governamentais. Fui convidado pela Organização Internacional do Trabalho (OIT) para apresentálo no Fórum 2000 da Organização das Nações Unidas (ONU) em Genebra, em que

5 O encontro propiciou a publicação de um livro muito lido e usado por ativistas no campo da justiça na França (SAINATI \& BONELLI, 2001). Ampliações e atualizações do diagnóstico da punição da pobreza na França sob o jugo de esquemas no estilo estadunidense, propostas em Les Prisons de la misère, incluem Sainati e Schalchli (2007), Bonelli (2008) e Mucchielli (2008a). 
representantes de vários países insistiram para que eu viajasse a fim de fomentar a discussão política em diversas partes do mundo.

Foi difícil recusar esses convites, pois, em questão de meses, o livro foi traduzido e lançado em meia dúzia de países, desencadeando um dilúvio de telefonemas de universidades, centros de direitos humanos, governos municipais e regionais e as mais diversas organizações profissionais e políticas, todos eles ansiosos para debater as implicações do livro em nações tão distantes como a Itália e o Equador, o Canadá e a Hungria, a Finlândia e o Japão. Na península ibérica, Les prisons de la misère foi logo traduzido não só para o espanhol, mas também para o catalão, o galego e o português. Na Bulgária, meu tradutor foi convidado para apresentar os argumentos da obra na televisão nacional, já que eu não pude viajar até Sófia para fazê-lo pessoalmente (WACQUANT, 2003). No Brasil, o lançamento da primeira edição de As prisões da miséria, patrocinado pelo Instituto Carioca de Criminologia e pelo Programa de Direito Criminal da Universidade Cândido Mendes, teve como atração principal um debate com o Ministro da Justiça e um ex-Governador do estado do Rio de Janeiro e foi coberto pelos principais jornais do país (talvez intrigados pelo título que eu dera à minha preleção: "Acaso a burguesia brasileira deseja restabelecer uma ditadura?") ${ }^{6}$. Poucas semanas depois a tese do livro era invocada por jornalistas, professores e advogados, além de ter sido citada em uma decisão do Supremo Tribunal Federal. Na Grécia seu lançamento ancorou uma conferência de dois dias, copatrocinada pela embaixada da França em Atenas, sobre "O Estado penal nos Estados Unidos, na França e na Grécia", reunindo cientistas sociais, juristas, historiadores, funcionários da Justiça e um grande número de repórteres. Na Dinamarca, a Associação Nacional de Assistentes Sociais patrocinou a publicação de De Fattiges foengsel como munição acadêmica para a resistência à assunção gradual e lenta da tarefa de supervisão punitiva dos pobres por assistentes sociais. Na Turquia, o livro circulou por meio da Escola para Diretores de Polícia do

\footnotetext{
6 Para uma análise mais completa das modalidades e implicações distintivas da contenção punitiva enquanto política antipobreza nos países da América Latina, ver Wacquant (2008b).
}

país, em uma tradução não-autorizada produzida por um comissário de polícia que o lera quando fazia seus estudos de Sociologia na França, até ser publicado em uma edição legal.

Mas foi a visita que fiz à Argentina em abril de 2000 que revelou mais claramente o quanto era sensível o nervo sociopolítico que o livro atingira. Foi a primeira vez que pus os pés naquele país. Não tinha nenhum conhecimento prévio de sua polícia, sua Justiça e suas instituições e tradições correcionais. No entanto, era como se eu tivesse formulado uma estrutura analítica destinada a apreender e esclarecer o que ocorria naquele exato momento na Argentina. Ao desembarcar em Buenos Aires, na fase final de uma acalorada campanha para as eleições municipais - em que tanto o candidatos da esquerda quanto o da direita haviam feito do combate ao crime com métodos inspirados pelos Estados Unidos sua prioridade máxima -, e apenas um mês depois de o apóstolo global da "tolerância zero", William Bratton, ter aportado na cidade para pregar seu evangelho político, vi-me apanhado no olho de um furacão intelectual, político e midiático. Em dez dias, fiz 29 palestras para plateias acadêmicas e de ativistas, mantive conversações com funcionários do governo e juristas e dei entrevista aos mais variados órgãos da imprensa escrita, de televisão e rádio. Ao cabo de uma semana, eu estava sendo parado nas ruas de Buenos Aires por transeuntes ansiosos por fazer mais perguntas sobre Las cárceles de la miseria.

Quero enfatizar que o objetivo desta recapitulação não é sugerir que a acolhida estrangeira a Prisões da miséria fornece medida adequada de seus méritos analíticos, mas dar uma ideia da ampla disseminação e da febre que o fenômeno que o livro investiga provoca nos campos político, artístico e intelectual de sociedades do Primeiro e do Segundo Mundo. O mundo vem sendo de fato assolado por uma tempestade de "lei e ordem", que transformou o debate público e a política sobre crime e punição de maneiras que nenhum observador da cena penal poderia ter previsto 12 anos atrás. A razão por detrás da inusitada paixão despertada pelo livro foi a mesma que na França. Em todos esses países, os mantras do policiamento com "tolerância zero" e da "prisão funciona", glorificado pelas autoridades estadunidenses e exibido pela dupla Giuliani-Bratton como a causa da queda 
aparentemente miraculosa da criminalidade em Nova York, estava sendo aclamado por funcionários locais. Em toda parte, políticos de direita e, o que é mais significativo, de esquerda ${ }^{7}$ competiam para importar os mais recentes métodos estadunidenses de imposição da lei, apresentados como panaceia para sanar a violência urbana e variadas modalidades de desordem, enquanto céticos e críticos desses métodos tentavam encontrar argumentos teóricos, dados empíricos e barreiras cívicas com os quais impedir a adoção do confinamento punitivo como técnica generalizada para o manejo da insegurança social descontrolada.

\section{SONDANDO O "CONSENSO DE WASHINGTON" SOBRE O COMBATE AO CRIME}

A rápida difusão internacional do livro transformou-se em um experimento nãoplanejado na política do conhecimento científico social. Ela revelou que, embora eu tivesse mirado com minha análise o cerne da União Europeia, o modelo do vínculo entre neoliberalismo e tratamento punitivo da insegurança nele esboçado era ainda mais pertinente à periferia do Velho Mundo, apanhada nos estertores da conversão pós-soviética, e aos países do Segundo Mundo marcados por uma história de autoritarismo, uma concepção hierárquica de cidadania e pobreza em massa, sustentada por desigualdades sociais excessivas e crescentes, nas quais a punição da pobreza certamente terá consequências calamitosas.

Dessa perspectiva, as sociedades latinoamericanas, que se haviam envolvido na experimentação precoce de uma desregulação econômica radical (isto é, rerregulação em favor de empresas multinacionais) e depois caído sob a

7 Apenas uma indicação sobre a Argentina: o principal panfleto de campanha do candidato de centro-esquerda Anibal Ibarrra, "Buenos Aires, un compromiso de todos", fez do combate ao crime o compromisso número um com os eleitores: "El compromiso de Ibarra-Felgueras: Con la seguridad: vamos a terminar con el miedo y a combatir el delito con la ley en la mano". Depois que apareci na televisão nacional para discutir Las cárceles de la miseria, os candidatos do Partido Peronista perguntaram-me, por meio de meu editor, se eu concordaria em aparecer com eles em uma entrevista coletiva para apoiar sua denúncia tática do compromisso de Ibarra com a "mano dura". tutela de organizações financeiras internacionais que impunham dogmas monetaristas, constituíam um terreno mais propício para a adoção de versões severas do populismo penal e a importação de estratagemas estadunidenses de combate ao crime. Em síntese: as elites dominantes das nações seduzidas, e depois transformadas, pelos "Chicago Boys" de Milton Friedman, nos anos 1970, estavam fadadas a apaixonar-se pelos "New York Boys" de Rudy Giuliani, nos anos 1990, quando chegou o momento de lidar com a proliferação das consequências da reestruturação neoliberal e enfrentar a instabilidade social endêmica e as perigosas desordens urbanas geradas pela reforma do mercado na base da estrutura de classes dualizante. Não foi por acaso que o Chile, o primeiro na América Latina a abraçar as políticas ditadas pelos "doutores do dinheiro" da Universidade de Chicago (VALDÉS, 1984), logo se tornou o campeão continental do encarceramento e viu sua taxa de aprisionamento saltar de 155 por 100 mil em 1992 para 240 em 100 mil em 2004, enquanto a taxa do Brasil saltou de 74 para 183 e a da Argentina de 63 para 140 (com a do Uruguai, preso entre eles, subindo de 97 para 220) (cf. INTERNATIONAL CENTER FOR PRISON STUDIES, 2007; SALLA \& RODRIGUEZ BALLESTEROS, 2008). Por todo o continente, há não apenas um agudo medo público da infecciosa criminalidade urbana, que cresceu lado a lado com disparidades econômicas na esteira do retorno do governo democrático e do descompromisso social do Estado, como também uma intensa preocupação política com os domínios e as categorias do problema. Há também um conjunto comum de soluções punitivas: a ampliação dos poderes e das prerrogativas da polícia, centrados em infrações de rua e infrações associadas às drogas; a aceleração e o endurecimento do processo judicial; a expansão da prisão como depósito; a normalização da "penalidade de emergência" aplicada de maneira diferencial através do espaço social e físico ${ }^{8}$, inspiradas ou legitimadas por panaceias vindas dos Estados Unidos, graças à diligente ação de diplomatas estadunidenses, órgãos judiciais americanos no exterior e de seus aliados locais, e à sede de políticos estrangeiros

\footnotetext{
8 Ver a acurada análise de Iturralde (2008) da rotinização
} da "penalidade de emergência" na Colômbia. 
por lemas e medidas para a imposição da lei embrulhadas no mana dos Estados Unidos ${ }^{9}$.

No hemisfério Sul, como na Europa Ocidental, o papel dos institutos de consultoria foi decisivo na difusão da punição agressiva "made in USA". Nos anos 1990, o Manhattan Institute encabeçou uma bem-sucedida campanha transatlântica para alterar os parâmetros da conduta britânica em relação à pobreza, ao welfare e ao crime. Uma década depois, ele desenvolveu o Inter-American Policy Exchange (IAPE), um programa concebido para exportar suas estratégias favoritas de combate ao crime para a América Latina como parte de um pacote de políticas neoliberais que compreendia "distritos de melhoramento dos negócios", reforma escolar por meio de comprovantes de despesas e contabilidade burocrática, redução do Estado e privatizações. Seus principais enviados foram ninguém menos que o próprio William Bratton, seu antigo assistente no Departamento de Polícia da cidade de Nova York William Andrews, e Geoge Kelling, o celebrado co-inventor da teoria das "janelas quebradas". Esses missionários da "lei e ordem" viajaram para o Sul a fim de encontrar-se não só com chefes de polícia e prefeitos de grandes cidades, mas também com governadores, ministros e presidentes. Respaldados pelo escritório permanente do IAPE em Santiago do Chile, fizeram um trabalho de propaganda entre institutos de consultoria de direita locais, braços da Câmara Americana de Comércio no país, organizações comerciais e ricos patrocinadores, proferindo conferências, oferecendo consultoria política e até participando de comícios cívicos certa feita Kelling fez um notável discurso em Buenos Aires para cerca de 10 mil argentinos reunidos em Luna Park para protestar contra a escalada da criminalidade ${ }^{10}$. Quando necessário, o IAPE ignora o nível nacional e trabalha com adversários regionais ou municipais do governo

\footnotetext{
9 Uma hábil dissecação da velha interseção entre a política externa dos Estados Unidos e normas e metas da Justiça Criminal é encontrada em Nadelmann (1994).

10 Os aliados do Manhattan Institute na América do Sul incluem o Instituto Liberal, a Fundação Victor Civita e a Fundação Getúlio Vargas no Brasil; o Instituto Libertad y Desarrollo e a Fundación Paz Ciudadana no Chile e a Fundación Libertad na Argentina. A fé cega na possibilidade de passar diretamente a "tolerância zero", apesar das vastas diferenças sociais, políticas e burocráticas entre os dois continentes, é expressa por Bratton e Andrew (2001).
}

central para promover seus remédios prómercado e pró-policiamento. Foi o que ocorreu na Venezuela, em que o esquerdista Presidente Hugo Chávez deseja combater o crime reduzindo a pobreza e a desigualdade, enquanto seus adversários políticos, como o Prefeito de Caracas, partilham a ideia do Manhattan Institute de que os responsáveis pelos crimes são os criminosos, e a missão de reprimi-los recai somente sobre as forças da ordem.

O Manhattan Institute traduz para o espanhol e para o português seus relatórios, resumos de programas e os artigos dos meios de comunicação que apoiam sua visão e distribui-os para formadores de opinião em toda a América do Sul. Também leva grupos de funcionários latinoamericanos à cidade de Nova York para visitas de campo, sessões de treinamento e doutrinação intensiva sobre as virtudes do Estado mínimo (nos planos social e econômico) e da imposição severa da lei (para os crimes da classe baixa). Esse evangelismo "produziu uma geração inteira" de políticos latino-americanos para os quais "o Instituto Manhattan é o equivalente de um Vaticano ideológico" (DEPALMA, 2002) e sua concepção bifurcada do papel do Estado, sacrossanta: laissezfaire e permissivismo no topo, hostilidade e incapacitação na base. Esses políticos mostramse ansiosos em aplicar a imposição inflexível da lei e o encarceramento ampliado para salvaguardar as ruas e subjugar os tumultos que agitam suas cidades, apesar da corrupção desbragada da polícia, da falência processual de seus tribunais e da brutalidade perversa de cadeias e prisões em seus países natais, os quais asseguram que estratégias de mano dura traduzam-se rotineiramente em medo crescente do crime, da violência e "detenção e punição extralegais para pequenos delitos, entre os quais a ocupação de estilo militar e a punição coletiva de bairros inteiros" (DAMMERT \& MALONE, 2006) ${ }^{11}$.

É interessante notar que o magnetismo da punição ao estilo estadunidense e dos ganhos políticos que ela promete é tamanho que líderes eleitos por toda a América Latina continuaram a exigir respostas punitivas para os crimes de rua, mesmo depois que partidos de esquerda ascenderam ao poder e transformaram a região

11 Para uma ilustração da situação no Brasil, ler Resende (1995) e assistir ao premiado filme de José Padilha, Tropa de elite (2007). 
em um "epicentro de discordância com as ideias liberais e de resistência ao domínio econômico e político dos EUA" (HERSHBERG \& ROSEN, 2006, p. 432). Essa situação é bem exemplificada pela assinatura solene, por Andrés Manuel López Obrador, o progressista Prefeito da Cidade do México, de um contrato de US\$ 4,5 milhões (pagos por um consórcio de empresários locais encabeçado pelo homem mais rico da América Latina, Carlos Slim Herú) com a firma de consultoria Giuliani Partners para aplicar sua poção mágica da "tolerância zero" à capital mexicana, apesar da óbvia inadequação de suas medidas-padrão no nível do chão (LORPARD, 2003) ${ }^{12}$. Um exemplo: os esforços para eliminar camelôs e flanelinhas (crianças, em sua maioria) mediante frequentes intervenções da polícia estão condenados ao fracasso, em razão de seus números absolutos (dezenas de milhares) e do papel central que eles desempenham na economia informal da cidade e, portanto, na reprodução de famílias de classe baixa, cujo apoio eleitoral é essencial para Obrador. Isso para não mencionar o fato de que a própria polícia mexicana está profundamente envolvida em todo tipo de comércio informal, legal e ilegal, necessário para suplementar seus salários de fome. Mas isso não importa. O que conta no México, como em Marselha ou em Milão, é menos a adoção de estratégias realistas para a redução do crime e mais a encenação da decisão das autoridades de combatê-lo frontalmente, de modo a reafirmar, de maneira ritual, o poder dos governantes.

A reação internacional a Prisões da miséria e os desdobramentos na Justiça Criminal ao longo da década de 2000 em países tão diferentes quanto a Suécia, a França, a Espanha e o México confirmaram não só que a "brattonmania" tornouse (quase) global, mas também que a disseminação da "tolerância zero" faz parte de um tráfego internacional mais amplo de fórmulas políticas que une o império do mercado, a redução dos gastos sociais e a ampliação penal ${ }^{13}$. O "Consenso de

12 Um breve relato do "furacão de 36 horas por ruas sórdidas e apartamentos elegantes" na Cidade do México "pelo consultor mais bem pago do mundo no quesito combate ao crime" é oferecido por Weiner (2003).

13 Para exemplos, ver Tham (2001) para a Suécia, MedinaAriza (2006) para a Espanha, Davis (2007) para o México e Mucchielli (2008b) para a França.
Washington" sobre a desregulação econômica e a retração do welfare estendeu-se para abranger, de fato, o controle punitivo do crime em uma chave pornográfica e gerencialista, pois a "mão invisível" do mercado suscita o "punho de aço" do Estado penal. A correspondência entre seus padrões geográficos e temporais de propagação corrobora minha tese central de que o rápido crescimento e a exaltação da polícia, dos tribunais e das prisões nas sociedades do Primeiro e do Segundo Mundo nas duas últimas décadas são um elemento essencial da revolução neoliberal. Onde quer que esses últimos avanços desencadeiem-se, a desregulação do mercado de trabalho de baixos salários exige a reforma restritiva do welfare para impor trabalho precário ao proletariado pós-industrial.

Essas duas coisas, por sua vez, provocam a ativação e a ampliação do braço penal do Estado: em primeiro lugar, para reprimir e conter os deslocamentos urbanos causados pela difusão da insegurança social na base da hierarquia de classes e espacial; em segundo lugar, para restaurar a legitimidade de líderes políticos desacreditados por sua aquiescência ou adesão à impotência do leviatã nas frentes social e econômica (WACQUANT, 2008c). A contrario, onde quer que a neoliberalização tenha sido impedida nos campos do emprego e do welfare, o impulso para a punição foi atenuado ou desviado, como indica, por exemplo, a obstinada surdez dos países nórdicos ao canto das sereias da "tolerância zero" (apesar de seu maior zelo em punir infrações associadas a drogas e a direção alcoolizada durante a década de 2000) ${ }^{14}$ e a estagnação ou os modestos aumentos de suas populações carcerárias, ainda que a preocupação ou a angústia nacional associada à criminalidade tenha aumentado.

\section{O QUE AS VIAGENS E OS ESFORÇOS DA PENALIDADE NEOLIBERAL TÊM A ENSINAR}

Assim, o que As prisões da miséria propõem é que suplementemos, ou mesmo suplantemos,

14 Um indicador: em toda uma década de publicação do Journal of Scandinavian Studies in Criminology and Crime Prevention, não há uma referência sequer a William Bratton ou a Rudolph Giuliani e somente 11 menções a "tolerância zero". Isso deixa bem clara a inaplicabilidade do conceito ao ambiente nórdico. 
os modelos evolucionários que dominaram os debates teóricos recentes sobre mudança penal em sociedades avançadas com uma análise descontinuísta e difusionista que rastreie a circulação de discursos, normas e políticas punitivas elaborados nos Estados Unidos como ingredientes constitutivos do governo neoliberal da desigualdade social e da marginalidade urbana.

$\mathrm{Na}$ visão da "sociedade exclusiva", proposta por Jock Young, e na descrição da "cultura do controle", feita por David Garland, bem como nas mais recentes concepções eliasianas, neodurkheimianas e neofoucaultianas da penalidade (YOUNG, 1999; 2007; GARLAND, 2001; PRATT, 2002; BOUTELLIER, 2004; O'MALLEY, 1998; SIMON, 2007), as mudanças contemporâneas na reconfiguração política do crime e da punição resultam da chegada a um estágio social - modernidade tardia, pósmodernidade e sociedade de risco - e despontam, de maneira endógena, em resposta ao aumento da insegurança criminal e suas reverberações culturais por todo o espaço social. No modelo delineado em Prisões da miséria (e revisado em publicações subseqüentes), a virada punitiva da política pública, aplicando-se tanto ao welfare quanto à Justiça Criminal, faz parte de um projeto político que responde à crescente insegurança social e a seus efeitos desestabilizadores nos degraus mais baixos da ordem social e espacial.

Esse projeto envolve a reorganização e a realocação do Estado para reforçar mecanismos semelhantes ao mercado e disciplinar o novo proletariado pós-industrial, restringindo, ao mesmo tempo, os distúrbios internos gerados pela fragmentação da mão de obra, a redução dos esquemas de proteção social e a reorganização correlata da hierarquia étnica estabelecida (etnoracial nos Estados Unidos, etnonacional na Europa Ocidental e uma mistura das duas na América Latina) (WACQUANT, 2010b) ${ }^{15}$. Mas a fabricação do novo leviatã também registra as influências externas de operadores políticos e empreendedores intelectuais, envolvidos em uma campanha de propaganda ideológica em múltiplos níveis através de fronteiras nacionais em assuntos de capital, mão de obra, welfare e imposição da lei. Embora o neoliberalismo seja, desde sua geração, uma formação que ocorre em múltiplos lugares, policêntrica e geograficamente irregular (PECK \& THEODORE, 2007), na virada do século essa campanha para reformar o nexo triádico de Estado, mercado e cidadania a partir de cima teve um centro nervoso localizado nos Estados Unidos, um anel interno de países colaboradores atuando como estações de retransmissão (como o Reino Unido, na Europa Ocidental, e o Chile, na América do Sul) e uma faixa externa de sociedades escolhidas como alvos de infiltração e conquista.

Pode-se expor o contraste teórico entre a visão da mudança penal propostas por advogados da transição para a modernidade tardia ou pósmodernidade e o modelo esboçado em Prisões da miséria. Para o primeiro modelo, a ascensão da punitividade é uma formação cultural que expressa os dilemas da sociedade que responde a tendências e padrões criminais; para o segundo, a restrição simultânea do Estado do Bem-estar e a expansão da prisão marcam um desvio do gerenciamento social para o gerenciamento penal da marginalidade urbana. Ela é parte e parcela da refeitura do Estado para alimentar a desregulamentação econômica e restringir as conseqüências da difusão da insegurança social na base das dimensões de classe, etnicidade e lugar. Há áreas de superposição entre essas duas abordagens, particularmente na sua rejeição comum a perspectivas criminológicas estreitamente focadas no par crime-punição, no seu desejo de unir punição a aspectos mais amplos das sociedades contemporâneas e na sua preocupação com a dimensão cultural da penalidade. Não obstante, é importante enfatizar suas divergências, em particular no papel que atribuem à questão da pobreza, da hegemonia internacional e dos operadores transnacionais na restauração do discurso penal e ação no limiar do novo século.

\footnotetext{
15 Ver também as respostas a esse ensaio dadas por Campbell (2010), Harcourt (2010), Mayer (2010), Peck (2010), Piven (2010) e Valverde (2010)
} 
QUADRO 1 - COMPARAÇÃO ENTRE AS VISÕES SOBRE A MUDANÇA PENAL

\begin{tabular}{|c|c|c|}
\hline & $\begin{array}{l}\text { MODERNIDADE TARDIA, PÓS- } \\
\text { MODERNIDADE }\end{array}$ & NEOLIBERALISMO \\
\hline Teóricos & Young, Garland, Pratt, Simon & Wacquant \\
\hline Motivador & $\begin{array}{l}\text { Estágio da sociedade: modernidade tardia, } \\
\text { pós-modernidade, sociedade do risco }\end{array}$ & $\begin{array}{l}\text { Projeto político: neoliberalismo como } \\
\text { modelador do Estado }\end{array}$ \\
\hline Origem & Endógena: evolução & $\begin{array}{c}\text { Misturada: evolução e difusão } \\
\text { (operadores transnacionais) }\end{array}$ \\
\hline Ativador & $\begin{array}{c}\text { Insegurança criminal: incidência e padrões } \\
\text { de infrações }\end{array}$ & $\begin{array}{l}\text { Insegurança social: fragmentação do } \\
\text { trabalho e suas conseqüências }\end{array}$ \\
\hline Veículo & $\begin{array}{l}\text { Políticas criminais e cultura do crime e do } \\
\text { controle }\end{array}$ & Workfare e Prisonfare ${ }^{i 6}$ Juntos \\
\hline Alvo & Por meio do espaço social & $\begin{array}{c}\text { Degraus mais baixos das hierarquias de } \\
\text { classe, étnicas e espaciais }\end{array}$ \\
\hline
\end{tabular}

FONTE: 0 autor.

Com poucas e preciosas exceções, os estudiosos estadunidenses da punição ignoraram as ramificações externas dos esquemas de polícia, justiça e encarceramento, forjados pelos Estados Unidos em reação à desintegração do contrato fordisto-keynesiano e ao colapso do gueto negro, quando não as negaram ${ }^{17}$. No entanto, ajustar contas com essa disseminação através de fronteiras - que trouxe para as costas europeias não somente o policiamento com tolerância zero mas também toques de recolher noturnos e monitoramento eletrônico, programas de curta duração, de inspiração militar, para adolescentes problemáticos e "encarceramento de choque" préjulgamento, redução de pena em troca de

16 "Prisonfare" é um termo introduzido pelo autor em analogia a workfare para designar programas de penalização da pobreza via direcionamento preferencial e emprego ativo da polícia, dos tribunais e das prisões (bem como suas extensões: liberdade vigiada, liberdade condicional, bases de dados de criminosos e sistemas variados de vigilância), no interior e nas proximidades dos bairros marginalizados em que se aglomera o proletariado pós-industrial (N. T.)

17 No momento mesmo em que a difusão transatlântica das categorias e políticas penais estadunidesens estava no auge, Tonry escreveu que "os Estados Unidos, em particular, não são nem importadores bem-sucedidos nem exportadores influentes" das medidas de combate ao crime, afirmando que "os países da Europa Ocidental imitam ativamente inovações à primeira vista bem-sucedidas de outras partes da Europa, mas parecem quase totalmente impermeáveis à influência estadunidense" (TONRY, 2001, p. 519). Um panorama amplo de estudos recentes das Ciências Sociais sobre o "Estado carcerário" nos Estados Unidos é sintomaticamente mudo a respeito das ramificações externas dos desdobramentos estadunidenses (GOTTSCHALK, 2008). reconhecimento de culpa e sentenças mínimas obrigatórias, registros de infratores sexuais e a transferência de jovens para a justiça adulta - é a chave para elucidar as análises e a política da penalidade neoliberal.

Em primeiro lugar, ela revela as conexões diretas entre desregulação de mercado, redução do welfare e expansão penal, colocando em foco sua difusão conjunta ou sequencial de um país para outro. É revelador, por exemplo, que o Reino Unido tenha adotado em primeiro lugar a política de gestão flexível da mão de obra e em seguida o projeto de workfare compulsório lançado pelos Estados Unidos, antes de importar deles o vocabulário agressivo de controle do crime e programas adequados para dramatizar o renascido rigor moral e a severidade penal das autoridades (KING \& WICKHAM-JONES, 1999; PECK \& THEODORE, 2001; JONES \& NEWBURN, 2002).

Em segundo lugar, rastrear a circulação internacional das fórmulas penais dos Estados Unidos ajuda-nos a evitar a armadilha conceitual da excepcionalidade estadunidense, bem como investigações nebulosas sobre a "modernidade tardia", já que aponta para os mecanismos que impulsionam o crescimento do Estado penal - ou, em alguns casos, para os obstáculos e vetores que resistem a ele - em um espectro de sociedades sujeitas ao mesmo tropismo político-econômico. Convida-nos a visualizar a ascensão do Estado penal nos Estados Unidos não como um caso idiossincrático, mas como um caso particularmente virulento, em razão de um grande número de fatores que se combinam para facilitar, acelerar e intensificar a contenção punitiva da insegurança social naquela sociedade, entre os 
quais a fragmentação do campo burocrático, a força do individualismo moral que sustenta o princípio mântrico da "responsabilidade retroativa individual", a degradação generalizada da mão de obra, os níveis excepcionalmente elevados de segregação tanto de classe quanto étnica, e a proeminência e a rigidez da divisão racial que faz dos negros da classe baixa e moradores nas áreas centrais degradadas das grandes cidades alvos propícios para campanhas convergentes de redução do welfare e de escalada penal (WACQUANT, 2010a; 2011).

Finalmente, há uma relação circular entre inovação e imitação policial em nível local (municipal ou regional), nacional e internacional, de tal modo que a pesquisa da globalização da "tolerância zero" e da ideia da eficácia prisional fornece um caminho proveitoso para a dissecação dos processos de seleção e tradução de noções e medidas penais através de jurisdições e níveis de governo que, em geral, passam despercebidos ou ficam sem análise dentro de um dado país. Ela proporciona novas revelações sobre a fabricação da vulgata neoliberal reinante, que transformou debates políticos em toda parte, por meio da difusão planetária dos conceitos e das preocupações populares dos formuladores de políticas e estudiosos estadunidenses. Ao exportar suas teorias e políticas penais, os Estados Unidos instituem-se como o barômetro do controle sério do crime no mundo todo e legitimam efetivamente sua visão da imposição da lei mediante a universalização de suas particularidades ${ }^{18}$.

A contrario, o rastreamento da difusão que cruza as fronteiras das fórmulas e medidas penais made in USA levanta de uma forma aguda a questão das bases sociais e culturais de resistência política à punitividade: como a Alemanha e a Escandinávia, na Euorpa Ocidental, o Canadá, na América do Norte, e o Japão, na Ásia Oriental, conseguiram permanecer impermeáveis ou reticentes à conclamação pela intensificação da punição e pela expansão do

18 Não é por acaso que os Estados Unidos exportaram, simultaneamente, suas noções populares - e as políticas a elas relacionadas - de crime com o "tolerância zero", de pobreza com a lenda da "subclasse" e de raça definida por (hipo)descendência (ver BOURDIEU \& WACQUANT, 1999). encarceramento? É exatamente porque esses países foram menos longe na estrada da desregulação econômica, da disparidade de classe e de empobrecimento urbano ou porque eles estão ficando para trás na transição da supervisão social para a supervisão penal da pobreza? Ou exercitam combinações específicas de controle social próximo, valores culturais, organização burocrática, autoridade de expertos e compromisso cívico com a inclusão que os capacitam a repelir pressões para um encarceramento mais elevado, mesmo quando suas políticas penais tornam-se mais diligentes e severas e afastam-se da reabilitação, como ilustrado pela trajetória recente do Japão (JOHNSON, 2007) ${ }^{19}$ ?

Como primeiro estudo com dimensão de livro sobre a difusão transnacional da penalidade ao estilo estadunidense no fim do século XX, As prisões da miséria antecipou o florescimento do campo da "transferência de políticas" de polícia e justiça (cf., em particular, NEWBURN \& SPARKS, 2004; ANDREAS \& NADELMANN, 2006; JONES \& NEWBURN, 2006; MUNCIE \& GOLDSON, 2006). Como tal, é uma contribuição indireta para a pesquisa sobre a globalização do crime e da justiça do ponto de vista da punição, mas uma contribuição que segue na direção contrária dos estudos da globalização feitos até hoje, uma vez que insiste em que o que parece um movimento cego e benigno rumo à convergência planetária, supostamente fomentado pela unificação tecnológica e cultural da sociedade mundial, é na verdade um processo estratificado de americanização diferencial e difratada, promovido pelas atividades estratégicas de redes hierárquicas de governantes, empreendedores ideológicos e marqueteiros acadêmicos nos Estados Unidos e nos países receptores. É também um apelo para que os estudiosos da migração de políticas no cenário mundial introduzam o domínio penal em seu campo, lado a lado com políticas econômicas e de welfare, e prestem atenção ao papel determinante exercido

19 Entre os títulos de uma literatura pouco numerosa, mas que cresce rapidamente, sobre divergência e diverificação penais em sociedades avançadas, cf. Oberwittler e Höfer (2005), Cavadino e Dignan (2006), Doob e Webster (2006), Lacey (2008) e Pratt (2008a; 2008b). 
por institutos de consultoria e disciplinas e cursos heteronômicos nas peregrinações internacionais de fórmulas de políticas públicas ${ }^{20}$.

As viagens de As prisões da miséria através de fronteiras nacionais, como o impetuoso movimento da onda punitiva que o livro segue no mundo todo, ensinaram-me que a difusão da penalidade neoliberal está não apenas mais avançada, como também é mais diversificada e complexa do que a retratada no livro. Assim como há variedades de capitalismo, há muitos caminhos rumo ao império do mercado e, portanto, muitas vias possíveis para a punição da pobreza. A própria punição assume u'a multiplicidade de formas, não se limitando ao encarceramento: ela infiltra-se por meio dos diferentes setores da polícia, da Justiça e dos aparatos carcerários, com efeitos variáveis; estendese por domínios da política, intrometendo-se na provisão de outros bens públicos como serviços médicos, assistência à infância e habitação; em geral desperta reticências, muitas vezes encontra resistências e por vezes provoca vigorosos contraataques $^{21}$. Além disso, o material e os componentes discursivos da política penal podem ficar dissociados e viajar separadamente, levando a acentuar, de maneira hiperbólica, a missão simbólica da punição como veículo para categorizar e estabelecer fronteiras. Tudo isso exige que se corrija e aperfeiçoe-se o modelo rudimentar do nexo

20 Uma respeitada revisão das pesquisas sociais sobre a difusão transnacional de políticas públicas não faz referência alguma a crime e punição e contém uma única menção aos institutos de consultoria (DOBBIN, SIMMONS \& GARRETT, 2007).

21 Essa mistura, evidenciada em uma descrição provocativa das influências estadunidenses e internacionais nas tendências recentes à "repunição" do crime juvenil e das reações que elas suscitam, é apresentada por Muncie (2008). entre neoliberalismo e penalidade punitiva esboçado em As prisões da miséria.

Essa foi a tarefa empreendida em Punir os pobres: a nova gestão da miséria nos Estados Unidos (WACQUANT, 2009b). Esse livro rompe os parâmetros usuais da economia política da punição, trazendo seus desdobramentos no welfare e na justiça criminal para uma única moldura teórica igualmente atenta ao instrumental e aos momentos expressivos da política pública. Ele utiliza o conceito de Pierre Bourdieu de "campo burocrático" para mostrar que as mudanças em políticas sociais e penais em sociedades avançadas no último quartel de século estão mutuamente vinculadas (BOURDIEU, 1994); que o workfare mesquinho e o prisonfare generoso constituem uma única geringonça organizacional para disciplinar e supervisionar os pobres sob uma filosofia de comportamentalismo moral e que um sistema penal expansivo e dispendioso não é uma consequência do neoliberalismo, como afirmado em Prisões da miséria, mas um componente essencial do próprio Estado neoliberal. O fato é que os esforços contemporâneos da penalidade fazem parte de uma reengenharia e de uma remasculinização mais ampla do Estado que tornou obsoleta a separação acadêmica e política convencional entre welfare e crime. A polícia, os tribunais e a prisão não são meros implementos técnicos mediante os quais as autoridades reagem ao crime - como quer a visão de senso comum cultuada pelo Direito e pela Criminologia -, mas capacidades políticas essenciais por meio das quais o leviatã produz e, ao mesmo tempo, gera a desigualdade, a marginalidade e a identidade. Isso ilumina a necessidade de desenvolver uma Sociologia Política do retorno do Estado penal ao primeiro plano do palco histórico no início do século XXI, um projeto para o qual As prisões da miséria é tanto um prelúdio quanto um convite.

Loïc Wacquant (loic@uclink4.berkeley.edu) é professor de Sociologia na Universidade da Califórnia (campus de Berkeley) (Estados Unidos) e pesquisador no Centre Européen de Sociologie et de Science Politique (França).

\section{REFERÊNCIAS BIBLIOGRÁFICAS}

ANDREAS, P. \& NADELMANN, E. 2006. Policing the Globe: Criminalization and Crime Control in International Relations. Nova York: Oxford University.
BOJE, T. 1993. (ed.). Post-Industrial Labour Markets: Profiles of North America and Scandinavia. Londres: Routledge. 
BONELLI, L. 2008. La France a peur. Une histoire sociale de l'insécurité. Paris: La Découverte.

BOURDIEU, P. 1994. Rethinking the State: On the Genesis and Structure of the Bureaucratic Field. Sociological Theory, Washington(DC), v. 12, n. 1, p. 1-19, Mar.

BOURDIEU, P. \& WACQUANT, L. 1999. On the Cunning of Imperialist Reason. Theory, Culture, and Society, London, v. 16, n. 1, p. 41-57, Feb. Disponível em: http:// www.loicwacquant.net/assets/Papers/ CUNNINGIMPERIALISTREASON.pdf. Acesso em: 19.dez.2011.

BOUTELLIER, H. 2004. The Safety Utopia: Contemporary Discontent and Desire as to Crime and Punishment. Dordrecht: Kluwer.

BRATTON, W. \& ANDREWS, W. 2001. Driving Out The Crime Wave: The Police Methods that Worked in Nova York City Can Work in Latin America. Time, July 23rd.

CAMPBELL, J. 2010. Neoliberalism's Penal and Debtor States: A rejoinder to Loïc Wacquant. Theoretical Criminology, London, v. 14, n. 1, p. 59-73, Feb.

CAVAdinO, M. \& DIGNAN, J. 2006. Penal System: A Comparative Approach. London: Sage.

DAMMERT, L. \& MALONE, M. F. T. 2006. Does It Take a Village? Policing Strategies and Fear of Crime in Latin America. Latin American Politics \& Society, Miami, v. 48, n. 4, p. 27-51, Dec.

DAVIS, D. E. 2007. El factor Giuliani: delincuencia, la "cero tolerância" en el trabajo policiaco y la transformación de la esfera pública en el centro de la ciudad de México. Estudios Sociológicos, Ciudad de México, v. 25, p. 639-641. Disponível em: http://redalyc.uaemex.mx/src/ inicio/ArtPdfRed.jsp?iCve=59825302. Acesso em: 19.dez.2011.

DEPALMA, A.2002. The Americas Court a Group That Changed New York. New York Times, November 11th. Disponível em: http:// www.nytimes.com/2002/11/11/nyregion/theamericas-court-a-group-that-changed-newyork.html?pagewanted $=$ all\&src $=$ pm. Acesso em: 19.dez.2011.
DOBBIN, F.; SIMMONS, B. \& GARRETT, G. 2007. The Global Diffusion of Public Policies: Social Construction, Coercion, Competition, or Learning? Annual Review of Sociology, Palo Alto, v. 33, p. 449-472.

DOOB, A. N. \& WEBSTER, C. M. 2006. Countering Punitiveness: Understanding Stability in Canada's Imprisonment Rate. Law \& Society Review, London, v. 40, n. 2, p. 325368 , June.

ESPING-ANDERSEN, G. \& REGINI, M. 2004 Why Deregulate Labour Markets? Oxford: Oxford University.

GARLAND, D. 2001. The Culture of Control: Crime and Social Order in Contemporary Society. Chicago: University of Chicago.

GOTTSCHALK, M. 2008. Hiding in Plain Sight: American Politics and the Carceral State. Annual Review Political Science, Palo Alto, v. 11 , p. $235-60$.

HANDLER, J. F. 2004. Social Citizenship and Workfare in the United States and Western Europe: The Paradox of Inclusion. Cambridge: Cambridge University.

HARCOURT, B. 2010. Neoliberal Penality: A Brief Genealogy. Theoretical Criminology, London, v. 14 , n. 1, p. 74-92, Feb.

HERSHBERG, E. \& ROSEN, F. 2006. Latin America After Neoliberalism: Turning the Tide in the 21st Century? New York: New.

INTERNATIONAL CENTER FOR PRISON STUDIES. 2007. World Prison Brief. London: King's College.

ITURRALDE, M. 2008. Emergency Penality and Authoritarian Liberalism: Recent Trends in Colombian Criminal Policy. Theoretical Criminology, London, v. 12, n. 3, p. 377-397, Aug.

JOHNSON, D. T. 2007. Crime and Punishment in Contemporary Japan. Crime and Justice: A Review of Research, v. 36, p. 371-423.

JONES, T. \& NEWBURN, T. 2002. Learning from Uncle Sam? Exploring US Influences on British Crime Control Policy. Governance: An International Journal of Policy, London, v. 15 , n. 1, p. 97-119, Dec 
2006. Policy Transfer and Criminal Justice. Maidenhead: Open University.

KING, D. \& WICKHAM-JONES, M. 1999. From Clinton to Blair: The Democratic (Party) Origins of Welfare to Work. Political Quarterly, London, v. 70, n. 1, p. 62-74, Jan.

KOCH, M. 2006. (ed.). Roads to Post-Fordism: Labour Markets And Social Structures in Europe. Aldershot: Ashgate.

LACEY, N. 2008. The Prisoners' Dilemma: Political Economy and Punishment in Contemporary Democracies. Cambridge (UK): Cambridge University.

LLOPART, J. P. 2003. Robocop in Mexico City. NACLA Report on the Americas, New York, v. 37, n. 2 .

MAYER, M. 2010. Punishing the Poor-A Debate. Some questions on Wacquant's Theorizing the Neoliberal State. Theoretical Criminology, London, v. 14, n. 1, p. 93-103, Feb.

MEDINA-ARIZA, J. 2006. The Politics of Crime in Spain, 1978-2004. Punishment \& Society, London, v. 8, n. 2, p. 183-201, Apr.

MUCCHIELLI, L. 2008a. (ed.) . La Frénésie sécuritaire. Retour à l'ordre et nouveau contrôle social. Paris: La Découverte.

2008b. Le «nouveau management de la sécurité » à l'épreuve: délinquance et activité policière sous le ministère Sarkozy (20022007). Champ Penal, Paris, v. 5.

MUNCIE, J. 2008. The "Punitive Turn" in Juvenile Justice: Cultures of Control and Rights Compliance in Western Europe and the USA. Youth Justice, London, v. 8, n. 2, p. 107121, Aug.

MUNCIE, J. \& GOLDSON, B. 2006. (ed.). Comparative Youth Justice. London: Sage.

NADELMANN, E. A. 1994. Cops Across Borders: The Internationalization of U.S. Criminal Law Enforcement. University Park: Pennsylvania State University.

NEWBURN, T. \& SPARKS, R. 2004. (eds.). Criminal Justice and Political Cultures: National and International Dimensions of Crime Control. London: Willan.

O'MALLEY, P. 1998. (ed.). Crime and the Risk Society. Aldershot: Ashgate.
OBERWITTLER, D. \& HÖFER, S. 2005. Crime and Justice in Germany: An Analysis of Recent Trends and Research. European Journal of Criminology, London, v. 2, n. 4, p. 465-508, Oct.

PECK, J. 2001. Workfare States. New York: Guilford.

2010. Zombie Neoliberalism and the Ambidextrous State. Theoretical Criminology, London, v. 14, n. 1, p. 104-110, Feb.

PECK, J. \& THEODORE, N. 2001. Exporting Workfare/Importing Welfare-to-Work: Exploring the Politics of Third Way Policy Transfer. Political Geography, v. 20, n. 4, p. 427-460.

2007. Variegated Capitalism. Progress in Human Geography, London, v. 31, n. 6, p. 731-772.

PIVEN, F. F. 2010. A Response to Wacquant. Theoretical Criminology, London, v. 14, n. 1, p. 111-116, Feb.

PRATT, J. 2002. Punishment and Civilization: Penal Tolerance and Intolerance in Modern Society. London: Sage.

2008a. Scandinavian Exceptionalism in an Era of Penal Excess. Part I: The Nature and Roots of Scandinavian Exceptionalism. British Journal of Criminology, Oxford, v. 48, n. 2, p. 119-137, Mar. Disponível em: http:// www.uio.no/studier/emner/jus/ikrs/ KRIM4001/h09/undervisningsmateriale/ pratt1.pdf. Acesso em: 19.dez.2011.

2008b. Scandinavian Exceptionalism in an Era of Penal Excess. Part II: Does Scandinavian Exceptionalism Have a Future? British Journal of Criminology, Oxford, v. 48 , n. 3, p. 275-292, May. Disponível em: http:// www.uio.no/studier/emner/jus/ikrs/ KRIM4001/h09/undervisningsmateriale/ pratt2.pdf. Acesso em: 19.dez.2011.

RESENDE, J. 1995. Operação Rio. Relato de uma guerra brasileira. São Paulo: Página Aberta.

SAINATI, G. \& BONELLI, L. 2001. (orgs.). La Machine à punir. Pratique et discours sécuritaires. Paris: L’Esprit frappeur.

SAINATI, G. \& SCHALCHLI, U. 2007. La Décadence sécuritaire. Paris: La Fabrique. 
SALLA, F. \& RODRIGUEZ BALLESTEROS, P. 2008. Democracy, Human Rights and Prison Conditions in South America. São Paulo: USP.

SIMON, J. 2007. Governing Through Crime: How the War on Crime Transformed American Democracy and Created a Culture of Fear. New York: Oxford University.

THAM, H. 2001. Law and Order as a Leftist Project? The Case of Sweden. Punishment \& Society, London, v. 3, n. 3, p. 409-426, July.

TONRY, M. 2001. Symbol, Substance, and Severity in Western Penal Policies. Punishment \& Society, London, v. 3, n. 4, p. 517-536, Oct.

TRICKEY, H. \& LOEDEMEL, I. 2001. (eds.). An Offer You Can't Refuse: Workfare in International Perspective. London: Policy.

VALDÉS, J. G. 1984. Pinochet's Economists: The Chicago School in Chile. Cambridge (UK): Cambridge University.

VALVERDE, M. 2010. Comment on Loïc Wacquant's 'Theoretical Coda' to Punishing the Poor. Theoretical Criminology, London, v. 14 , n. 1, p. 117-120, Feb.

WACQUANT, L. 2003. Towards a Dictatorship over the Poor? Notes on the Penalization of Poverty in Brazil. Punishment \& Society, London, v. 5, n. 2, p. 197-205, Apr. Disponível em: http://www.loicwacquant.net/assets/ Papers/DICTATORSHIPOOR.pdf. Acesso em: 19.dez.2011.

2008a. Urban Outcasts: A Comparative Sociology of Advanced Marginality. Cambridge (UK): Polity.

2008b. The Militarization of Urban Marginality: Lessons from the Brazilian Metropolis. International Political Sociology, London, v. 2, n. 1, p. 56-74, Mar. Disponível em: http://metrostudies.berkeley.edu/pubs/
reports/Wacquant_MILITARIZATION URBMARGBRAZIL-pub.pdf. Acesso em: 19.dez.2011.

2008c. Ordering Insecurity: Social Polarization and the Punitive Upsurge. Radical Philosophy Review, v. 11, n. 1, p. 9-27, Spring.

2009a. Prisons of Poverty. Minneapolis: University of Minnesota.

2009b. Punishing the Poor: The Neoliberal Government of Social Insecurity. Durham: Duke University.

2009c. The Body, the Ghetto and the Penal State. Qualitative Sociology, New York, v. 32, n. 1, p. 101-129. Disponível em: http:// cue.berkeley.edu/loic1.pdf. Acesso em: 19.dez.2011.

2010a. Class, Race and Hyperincarceration in Revanchist America. Dadalus, Boston, v. 139, n. 3, p. 74-90, Summer.

2010b. Crafting the Neoliberal State: Workfare, Prisonfare and Social Insecurity. Sociological Forum, London, v. 25, n. 2, p. 197-220, June. Disponível em: http:// www.loicwacquant.net/assets/Papers/ CRAFTINGNEOLIBERALSTATE-pub.pdf. Acesso em: 19.dez.2011.

2011. Deadly Symbiosis: Race and the Rise of the Penal State. Cambridge: Polity.

WEINER, T. 2003. Mexico City Journal; Enter Consultant Giuliani, His Fee Preceding Him. New York Times, January 16th. Disponível em: http://www.nytimes.com/2003/01/16/world/ mexico-city-journal-enter-consultant-giulianihis-fee-preceding-him.html. Acesso em: 19.dez.2011.

YOUNG, J. 1999. The Exclusive Society: Social Exclusion, Crime and Difference in Late Modernity. London: Sage.

2007. The Vertigo of Late Modernity. London: Sage. 


\section{THE GLOBAL FIRESTORM OF LAW AND ORDER: ON PUNISHMENT AND NEOLIBERALISM}

Lö̈c Wacquant

This article reflects on the international reception of the book Prisons of Poverty as revelator of penal developments in advanced societies over the past decade. It shows that the global firestorm of "law and order" inspired by the United States that the book detected in 1999 has continued to rage far and wide. Indeed, it has extended from First- to Second-World countries and has altered punishment politics and policies around the globe in ways that no one foresaw and would have thought possible some 15 years ago. It extends the analysis of the role of think tanks (especially the Manhattan Institute) in the diffusion of US-style crime-fighting notions and nostrums in Latin America as one element of the international circulation of pro-market policy packages fostering the punitive management of poverty. It elaborates and revises the original model of the link between neoliberalism and punitive penality, leading to the analysis of state-crafting in the age of social insecurity developed in the book Punishing the Poor.

KEYWORDS: Criminal Justice; Zero Tolerance; Think Tanks; Penal State; Policy Transfer; Neoliberalism; Globalization. 